\title{
Electronic Structural Changes of Mn in the Oxygen-Evolving Complex of Photosystem II During the Catalytic Cycle
}

\author{
Pieter Glatzel ${ }^{1, *}$, Henning Schroeder ${ }^{2}$, Yulia Pushkar $2, \dagger$, Thaddeus Boron III ${ }^{3}$, Shreya \\ Mukherjee $^{4}$, George Christou ${ }^{4}$, Vincent L. Pecoraro ${ }^{3}$, Johannes Messinger ${ }^{5}$, Vittal K. \\ Yachandra ${ }^{2,{ }^{*}, \text { Uwe Bergmann }}{ }^{6,{ }^{*}}$, and Junko Yano ${ }^{2,{ }^{*}}$ \\ ${ }^{1}$ European Synchrotron Radiation Facility, Grenoble, France \\ ${ }^{2}$ Physical Biosciences Division, Lawrence Berkeley National Laboratory, Berkeley, CA \\ ${ }^{3}$ Dept. of Chemistry, Univ. of Michigan, Ann Arbor, MI \\ ${ }^{4}$ Dept. of Chemistry, Univ. of Florida, Gainesville, FL \\ ${ }^{5}$ Institutionen för Kemi, Kemiskt Biologiskt Centrum, Umeå Universitet, Umeå, Sweden \\ ${ }^{6}$ LCLS, SLAC National Accelerator Laboratory, Menlo Park, CA
}

\begin{abstract}
The oxygen evolving complex (OEC) in Photosystem II (PS II) was studied in the $\mathrm{S}_{0}$ through $\mathrm{S}_{3}$ states using 1s2p direct resonant inelastic X-ray scattering (RIXS) spectroscopy. The spectral changes of the OEC during the S-state transitions are subtle, indicating that the electrons are strongly delocalized throughout the cluster. The result suggests that in addition to the $\mathrm{Mn}$ ions ligands are also playing an important role in the redox reactions. A series of $\mathrm{Mn}^{\mathrm{IV}}$ coordination complexes with different protonation states, nuclearity, and with and without the presence of $\mathrm{Ca}$ were compared, particularly with the PS II $\mathrm{S}_{3}$ state spectrum to understand its oxidation state. We find strong variations of the electronic structure within the series of $\mathrm{Mn}^{\mathrm{IV}}$ model systems. The spectrum of the $\mathrm{S}_{3}$ state best resembles the $\mathrm{Mn}^{\mathrm{IV}}$ complexes, $\mathrm{Mn}_{3}{ }^{\mathrm{IV}} \mathrm{Ca}_{2}$ and $\operatorname{saplnMn}{ }_{2}{ }^{\mathrm{IV}}(\mathrm{OH})_{2}$, i.e. the oxo-bridge protonation of $\mathrm{Mn}$ dimer complexes and the presence of $\mathrm{Ca}$ in one corner of a Mn cubane structure show a similar spectroscopic response, suggesting that $\mathrm{Ca}$ in PS II and protonation of the oxo-bridge may give rise to analogous modifications of the electronic structure at the $\mathrm{Mn}$ sites. The current result emphasizes that the assignment of formal oxidation states alone is not sufficient for understanding the detailed electronic structural changes that govern the catalytic reaction in the OEC.
\end{abstract}

The oxygen-evolving complex (OEC) located in the Photosystem II (PS II) membranebound protein in plants, algae, and cyanobacteria catalyzes the water-oxidation reaction. ${ }^{1}$ The OEC, an oxo-bridged complex of four $\mathrm{Mn}$ and one $\mathrm{Ca}$ ions $\left(\mathrm{Mn}_{4} \mathrm{CaO}_{5}\right.$ cluster), couples the 4-electron chemistry of water oxidation with the one-electron photochemistry of the reaction center by sequentially storing oxidizing equivalents through five intermediate $\mathrm{S}$ states $\left(\mathrm{S}_{\mathrm{i}}, \mathrm{i}=0\right.$ to 4$)$, before one molecule of dioxygen is evolved. The $\mathrm{Mn}_{4} \mathrm{CaO}_{5}$ cluster provides a high degree of redox and chemical flexibility so that several oxidizing equivalents can be stored during the $\mathrm{S}$-state cycle. To understand the mechanism of water

\footnotetext{
Corresponding Author: pieter.glatzel@esrf.fr, vkyachandra@lbl.gov, bergmann@slac.stanford.edu, jyano@lbl.gov.

†resent Addresses

Department of Physics, Purdue University, 525 Northwestern West Lafayette, Indiana, 47907, USA.

Supporting Information Available: Materials and methods.
} 
oxidation in detail, it is crucial to understand the changes of the electronic structure in the OEC over the whole course of the catalytic cycle. ${ }^{2}$

There is a consensus that Mn-centered oxidation occurs during the $S_{0}$ to $S_{1}$, and $S_{1}$ to $S_{2}$ transitions. However, there has been a long debate regarding the nature of the $S_{2}$ to $S_{3}$ transition. Within the context of localized oxidation, the formal oxidation state of the native $\mathrm{S}_{1}$ state has been assigned to $\mathrm{Mn}_{2}{ }^{\mathrm{III}} \mathrm{Mn}_{2}{ }^{\mathrm{IV}}$ and $\mathrm{S}_{2}$ to $\mathrm{Mn}^{\mathrm{III}} \mathrm{Mn}_{3}{ }^{\mathrm{IV}}$. In the $\mathrm{S}_{0}$ state, involvement of $\mathrm{Mn}^{\mathrm{II}}$ has been discussed, while recent ENDOR studies ${ }^{3}$ support the formal oxidation state of $\mathrm{Mn}_{3}{ }^{\mathrm{III}} \mathrm{Mn}^{\mathrm{IV}}$. In the $\mathrm{S}_{3}$ state, the question remains whether a Mn-centered oxidation occurs ${ }^{4}$ and therefore all $\mathrm{Mn}$ become $\mathrm{Mn}^{\mathrm{IV}}$, or a ligand-centered oxidation takes place before O-O bond formation and release of molecular oxygen. ${ }^{5}$ This incomplete understanding of the $\mathrm{S}_{2}$ to $\mathrm{S}_{3}$ transition has led to two different types of proposed $\mathrm{O}_{2}$ evolution mechanisms, with one type incorporating the nucleophilic attack mechanism of high-valent $\mathrm{Mn}$, and the other involving oxo-radicals. ${ }^{2,}{ }^{6}$ Fundamental differences in the chemistry of $\mathrm{O}-\mathrm{O}$ bond formation and $\mathrm{O}_{2}$ evolution exist between the two types of mechanisms.

In our earlier RIXS study it was shown that the electron in the $S_{1}$ to $S_{2}$ transition is removed from a strongly delocalized orbital, indicating strong covalency within the $\mathrm{Mn}_{4} \mathrm{CaO}_{5}$ cluster and that the oxidation therefore cannot be assigned to just one $\mathrm{Mn}$ atom in the OEC. ${ }^{7}$ In the current study, we present RIXS data on PS II from $S_{0}$ through the $S_{3}$ states of the OEC. We compared the $S_{3}$ spectrum with model compounds, where Mn has the formal oxidation state IV, with different nuclearities, types of ligands, and geometries.

In 1s2p RIXS spectroscopy (Scheme 1), a Mn 1s electron is excited into the lowest unoccupied molecular orbitals (LUMOs). The orbitals have mainly Mn 3d character mixed with $\mathrm{Mn} 4 \mathrm{p}$ and ligand orbitals. The electronic configuration can be approximated by $1 \mathrm{~s}^{1} 3 \mathrm{~d}^{\mathrm{n}+1}$ and the spectral features are the $\mathrm{K}$ absorption pre-edge. The excited states decay and release a photon whose energy is recorded in order to obtain the energy that remains in the sample (energy transfer). The most probable transition is $2 p$ to 1 s to reach the final state configuration $2 \mathrm{p}^{5} 3 \mathrm{~d}^{\mathrm{n}+1}$, which is formally identical to that of L-edge spectroscopy. The creation of inner-shell electron vacancies renders this technique element-selective and sensitive to both the metal ion charge and spin density.

RIXS spectra are shown as a two-dimensional contour plots (c.f. Figure 1) with incident energy and energy transfer along the axes. The spectral broadening along the energy transfer axis is not governed by the short core hole lifetime of the intermediate state, but the longer lived final state, resulting in sharp spectral features. Thus, RIXS spectroscopy considerably improves the pre-edge separation from the main edge feature as compared to XAS in which it is usually difficult to distinguish the contribution of strong main edge transition (seen as strong rising intensity in the highest energy region in Fig. 1). The main spectral features extend along a diagonal streak in the 1s $2 p$ RIXS plane. Spectral features off this diagonal line result from different interactions of the $1 \mathrm{~s}$ and the $2 \mathrm{p}$ core hole with the valence electrons. These direct Coulomb and exchange interactions are considerably stronger for a $2 \mathrm{p}$ core hole, making the technique also sensitive to the spin density of Mn.

Figure 1 shows RIXS spectra of PS II in the $\mathrm{S}_{0}$ to $\mathrm{S}_{3}$ states and a series of Mn model complexes. The $1 \mathrm{~s} 2 \mathrm{p}$ RIXS planes of $\mathrm{Mn}^{\mathrm{IV}}$ systems (Fig. $1 \mathrm{~b}-\mathrm{h}$, chemical structures of $\mathrm{b}-\mathrm{g}$ shown in SI) vary significantly, demonstrating that a $\mathrm{Mn}^{\mathrm{IV}}$ species does not provide a single unique spectroscopic fingerprint. The spectral shape is strongly influenced by the local density of unoccupied electronic states. The $\mathrm{K}$ absorption pre-edges obtain spectral intensity from electric dipole and quadrupole transitions depending on the local symmetry. Therefore, the spectral intensity may vary considerably depending on the number and type of ligands. ${ }^{8}$ 
The coordination complexes in Fig. 1 all have six-coordinated Mn and the ratio between dipole and quadrupole contribution to the pre-edge will vary little. We attribute intensity variations to modifications in the composition of the molecular orbitals.

The overall trend observed in the 1s2p RIXS planes is a shift of spectral intensity to higher energies with increasing positive charge on the metal. The solid state system $\mathrm{Mn}^{\mathrm{IV}} \mathrm{O}_{2}$ (Fig. $1 \mathrm{~h}$ ) has its highest energy peak at $6542.9 \mathrm{eV}$, representing the most ionic form of $\mathrm{Mn}^{\mathrm{IV}}$ possibly induced by the extended structure of the $\mathrm{Mn}-\mathrm{O}$ lattice. The $\mathrm{Mn}^{\mathrm{IV}}$ coordination complexes (Fig. 1b-g) ${ }^{9}$ are distinctly different from the oxides. They show three main spectral features in the energy range of $6539-6544 \mathrm{eV}$. The low energy feature at $6541 \mathrm{eV}$ (indicated as 1 in Fig. 1b) is sharper than the structures at higher energies. It corresponds to the excitations of $1 \mathrm{~s}$ electron into LUMOs that are localized, and therefore exhibit a more atomic character. The effect of the ligand environment becomes more dominant towards higher energies (6541-6544 eV, indicated as 2 in Fig. 1b), resulting in broader spectral features due to the orbital splittings. The intensity around $6542 \mathrm{eV}$ appears off-diagonal (indicated as 3 in Fig. 1b), shifted towards higher energy transfer which is caused by strong $(2 \mathrm{p}, 3 \mathrm{~d})$ electron-electron interactions.

A series of di- $\mu$-oxo bridged $\mathrm{Mn}$ salpn compounds $\left(\operatorname{salpn}_{2} \mathrm{Mn}_{2}{ }^{\mathrm{IV}}(\mathrm{OH})_{2}, \operatorname{salpn}_{2} \mathrm{Mn}_{2}{ }^{\mathrm{IV}} \mathrm{OOH}\right.$, and salpn ${ }_{2} \mathrm{Mn}_{2}{ }^{\mathrm{IV}} \mathrm{O}_{2}$, Fig. $1 \mathrm{~b}-\mathrm{d}$ ) demonstrates the sensitivity of $1 \mathrm{~s} 2 \mathrm{p}$ RIXS to the sequential protonation of the bridging oxygen. They show a transfer of spectral intensity from low to the high energy features. Replacing $\mathrm{OH}^{-}$with $\mathrm{O}^{2-}$ thus results in a 1s2p RIXS plane with the spectral weight predominantly in the region where also $\mathrm{Mn}^{\mathrm{IV}} \mathrm{O}_{2}$ (Fig. 1h) shows its strongest spectral feature.

The spectra of $\mathrm{Mn}_{3}{ }^{\mathrm{IV}} \mathrm{O}_{4}$ Acbpy (Fig. 1g), salpn ${ }_{2} \mathrm{Mn}_{2}{ }^{\mathrm{IV}} \mathrm{O}_{2}$ (Fig. 1d), and phen ${ }_{4} \mathrm{Mn}_{2}{ }^{\mathrm{IV}} \mathrm{O}_{2}$ (Fig. 1e) show maximum intensity at higher energies $(6541-6544 \mathrm{eV})$ as opposed to other compounds (e.g. Figs. 1b, f). In all cases the di- $\mu$-oxo bridge is not protonated. This confirms that the bridging ligand including its degree of protonation has a strong influence on the electronic structure around Mn. The subtle differences at higher energies observed among the three compounds reflect the orbital modifications at the Mn sites when replacing $\mathrm{N}$ with $\mathrm{O}$ (SI Fig. S1) and slightly changing the bond distances and angles. $\mathrm{Mn}_{3}{ }^{\mathrm{IV}} \mathrm{O}_{4}$ Acbpy (Fig. 1g) with two di- $\mu$-oxo bridges and additonal $\mathrm{O}$ ligands have their main peak intensity at higher energy. The phen ${ }_{4} \mathrm{Mn}_{2}{ }^{\mathrm{IV}} \mathrm{O}_{2}$ complex (Fig. 1e) with $\mathrm{N}$ ligands and two di- $\mu$-oxo bridges, by contrast, shows spectral intensity at lower energies than salpn ${ }_{2} \mathrm{Mn}_{2}{ }^{\mathrm{IV}} \mathrm{O}_{2}$ (Fig. 1d) where each $\mathrm{Mn}$ has two additional $\mathrm{O}$ ligands. The spectrum of $\mathrm{Mn}_{3} \mathrm{Ca}_{2}$ (Fig. 1f) resembles salpn ${ }_{2} \mathrm{Mn}_{2}{ }^{\mathrm{IV}}(\mathrm{O})(\mathrm{OH})$ with single protonation of the oxo-bridge (Fig. 1c). The $\mathrm{Mn}_{3} \mathrm{Ca}_{2}$ compound contains a cubane-like structure that consists of a $\mathrm{Mn}_{3}{ }^{\mathrm{IV}} \mathrm{CaO}_{4}$ moiety. The presence of $\mathrm{Ca}$ within the cubane-like structure appears to modify the electronic structure of $\mathrm{Mn}$ in a similar way as we observe for protonation of the oxo-bridge.

Pure $S_{0}, S_{1}, S_{2}$, and $S_{3}$ spectra shown in Figs. 1 and 2 were obtained by the deconvolution of the flash illuminated samples using the calculated S-state distribution from EPR (see SI, Fig. S2a-c). Within the series of PS II data we observe a small shift of spectral intensity to higher energies between $\mathrm{S}_{0}$ and $\mathrm{S}_{3}$ confirming the oxidation at the Mn sites during the catalytic cycle. ${ }^{7}$ This is also observed in the XAS pre-edge spectra as shown in Fig. 2. A low energy shoulder appears in the $S_{0}$ pre-edge spectrum which is seen as a low energy component in the RIXS $S_{0}$ spectrum (Fig. 1). Upon the $S_{0}$ to $S_{1}$ transition, the low energy shoulder in the pre-edge spectra (Fig. 2) becomes weaker and the spectrum can be fitted with two strong components ( $\sim 6541.1$ and $\sim 6542.8 \mathrm{eV}$ ) in the $S_{1}$ to $S_{3}$ states. Note that the instrumental resolution for the PS II RIXS data in Fig. 1 is lower compared to the model compounds because the data were recorded at different experimental stations. However, the striking observation when comparing PS II and model compound data is that the spectral 
changes during the PS II catalytic cycle (Fig. 1) are considerably weaker than the spectral differences among the $\mathrm{Mn}^{\mathrm{IV}}$ coordination complexes.

In the $\mathrm{S}_{0}$ state, two different formal oxidation states, II,III, $\mathrm{IV}_{2}$ and $\mathrm{III}_{3}, \mathrm{IV}$, have been proposed from the previous EPR ${ }^{10}$, XANES ${ }^{5}$ and other studies. Recent ${ }^{55} \mathrm{Mn}$ ENDOR studies $^{3}$ have shown that the data are compatible with the formal oxidation state of $\mathrm{III}_{3}, \mathrm{IV}$. In RIXS, $\mathrm{Mn}^{\mathrm{II}}$ compounds show a characteristic feature due to the strong stabilizing energy of a $3 \mathrm{~d}^{5}{ }^{5} \mathrm{~S}$ valence shell configuration at around $\sim 6540 \mathrm{eV}$. Unlike $\mathrm{Mn}^{\mathrm{IV}}$ model compounds, $\mathrm{Mn}^{\mathrm{II}}$ in both the oxide ( $\mathrm{Mn}^{\mathrm{II}} \mathrm{O}$, Fig. 1a) and coordination complexes (not shown here) have very similar spectral features. ${ }^{7}$ In the $\mathrm{S}_{0}$ state, both RIXS and XAS data show spectral intensity at low energies $(\sim 6540 \mathrm{eV})$, which could indicate a contribution of $\mathrm{Mn}^{\mathrm{II}}$. This low energy component becomes weak in the $\mathrm{S}_{0}$ to $\mathrm{S}_{1}$ transition. However, $\mathrm{Mn}^{\mathrm{III}}$ compounds may also show a low energy feature around $\sim 6540 \mathrm{eV}$ that originates from strong (3d, 3d) electron-electron interactions. ${ }^{7}$ Therefore, a comparison of the RIXS $\mathrm{S}_{0}$ spectrum with $\mathrm{Mn}^{\mathrm{II}} \mathrm{O}$ (Fig. 1a) does not confirm the presence or absence of $\mathrm{Mn}^{\mathrm{II}}$ in the $\mathrm{S}_{0}$ state. This would require a considerably larger set of experimental data combined with quantum chemical calculations of the spectra. The latter is currently not possible with the required accuracy due to the complexity of $3 \mathrm{~d}^{3}$ and $3 \mathrm{~d}^{4}$ systems, because the pre-edge is shaped by electric dipole and quadrupole transitions, and the current limitation of quantum chemical codes to include fully the core hole effect.

A comparison of the $\mathrm{S}_{3}$ RIXS spectrum with a series of $\mathrm{Mn}^{\mathrm{IV}}$ coordination compound spectra suggests that the electronic structure of $\mathrm{Mn}$ in the $\mathrm{S}_{3}$ state is much more similar to salpn ${ }_{2} \mathrm{Mn}_{2}{ }^{\mathrm{IV}}(\mathrm{OH})_{2}$ (Fig. 1b) rather than salpn ${ }_{2} \mathrm{Mn}_{2}{ }^{\mathrm{IV}} \mathrm{O}_{2}$ (Fig. 1d), phen ${ }_{4} \mathrm{Mn}_{2}{ }^{\mathrm{IV}} \mathrm{O}_{2}$ complex (Fig. 1e), $\mathrm{Mn}_{3}{ }^{\mathrm{IV}} \mathrm{O}_{4}$ Acbpy (Fig. 1g) or the oxide $\mathrm{Mn}^{\mathrm{IV}} \mathrm{O}_{2}$ (Fig. 1h).

The OEC goes through four redox states during the $S_{0}$ to $S_{3}$ state transitions. Our study shows that the RIXS spectral changes in PS II are considerably weaker than the changes observed within the $\mathrm{Mn}^{\mathrm{IV}}$ coordination complexes. They are also weaker than the spectral changes between Mn oxides. ${ }^{7}$ We, therefore, conclude that redox reactions of the OEC must be considered within the entire $\mathrm{Mn}_{4} \mathrm{CaO}_{5}$ entity. Namely, the ligands participate in the charge balancing. A description of the electronic structure at the Mn sites thus has to go beyond the assignment of formal oxidation states. We note that this does not contradict other studies such as EPR and ENDOR, because a different response is probed in the various techniques.

We have shown that the formal oxidation states may be insufficient for describing the complex nature of the electronic structure in multinuclear clusters like the $\mathrm{Mn}_{4} \mathrm{CaO}_{5}$ cluster in PS II. Electrons are strongly delocalized in the $\mathrm{Mn}_{4} \mathrm{CaO}_{5}$ cluster, and ligands may be intimately involved in the redox chemistry. As a consequence, the Mn RIXS spectral changes are subtle during the S-state transitions. Of the two main mechanisms that are being considered for the $\mathrm{O}-\mathrm{O}$ bond formation catalyzed by the $\mathrm{OEC}$, one involves the generation of a $\mathrm{Mn}^{\mathrm{V}}$-oxo group in the final step when the O-O bond is formed, and the alternate mechanism involves delocalization of the charge onto a ligand and the subsequent chemistry of O-O bond formation. ${ }^{6 \mathrm{~b}, 11}$ The current results show that the change of the electronic charge includes the ligands in all S-state transitions. Therefore, the mechanisms that rely on delocalization of charge on the ligands may become more relevant, and any proposed mechanism requires one to take this into account. Moreover, this suggests that such delocalization may play a role during the $\mathrm{O}-\mathrm{O}$ bond formation step in the $\mathrm{S}_{4}$ state.

\section{Supplementary Material}

Refer to Web version on PubMed Central for supplementary material. 


\section{Acknowledgments}

This work was supported by the NIH grant (GM 55302), and the DOE, Director, Office of Science, Office of Basic Energy Sciences (OBES), Chemical Sciences, Geosciences, and Biosciences Division, under Contract DEAC02-05CH11231. Parts of this research were carried out at ESRF, APS, and SSRL operated by Stanford University for DOE, OBES. We thank Dr. Sumit Bhaduri for providing model complexes.

\section{ABBREVIATIONS}

$\begin{array}{ll}\text { RIXS } & \text { Resonant Inelastic X-ray Scattering } \\ \text { XAS } & \text { X-ray Absorption Spectroscopy } \\ \text { PS II } & \text { Photosystem II } \\ \text { OEC } & \text { Oxygen Evolving Complex }\end{array}$

\section{References}

1. Wydrzynski, T.; Satoh, S. Photosystem II: The Light-Driven Water:Plastoquinone Oxidoreductase. Springer; Dordrecht: 2005.

2. Messinger J. Phys Chem Chem Phys. 2004; 6:4764-4771.

3. (a) Kulik LV, Epel B, Lubitz W, Messinger J. J Am Chem Soc. 2005; 127:2392-2393. [PubMed: 15724984] (b) Kulik LV, Epel B, Lubitz W, Messinger J. J Am Chem Soc. 2007; 129:1342113435. [PubMed: 17927172]

4. Iuzzolino L, Dittmer J, Dörner W, Meyer-Klaucke W, Dau H. Biochemistry. 1998; 37:1711217119. [PubMed: 9860823]

5. Messinger J, Robblee JH, Bergmann U, Fernandez C, Glatzel P, Visser H, Cinco RM, McFarlane KL, Bellacchio E, Pizarro SA, Cramer SP, Sauer K, Klein MP, Yachandra VK. J Am Chem Soc. 2001; 123:7804-7820. [PubMed: 11493054]

6. (a) McEvoy JP, Brudvig GW. Chem Rev. 2006; 106:4455-4483. [PubMed: 17091926] (b) Siegbahn PEM. Acc Chem Res. 2009; 42:1871-1880. [PubMed: 19856959] (c) Yamanaka S, Isobe H, Kanda K, Saito T, Umena Y, Kawakami K, Shen JR, Kamiya N, Okumura M, Nakamura H, Yamaguchi K. Chem Phys Lett. 2011; 511:138-145.(d) Saito T, Yamanaka S, Kanda K, Isobe H, Takano Y, Shigeta Y, Umena Y, Kawakami K, Shen JR, Kamiya N, Okumura M, Shoji M, Yoshioka Y, Yamaguchi K. Int J Quantum Chem. 2012; 112:253-276.(e) Kolling DRJ, Cox N, Ananyev GM, Pace RJ, Dismukes GC. Biophys J. 2012; 103:313-322. [PubMed: 22853909]

7. Glatzel P, Bergmann U, Yano J, Visser H, Robblee JH, Gu WW, de Groot FMF, Christou G, Pecoraro VL, Cramer SP, Yachandra VK. J Am Chem Soc. 2004; 126:9946-9959. [PubMed: 15303869]

8. (a) Westre TE, Kennepohl P, DeWitt JG, Hedman B, Hodgson KO, Solomon EI. J Am Chem Soc. 1997; 119:6297-6314.(b) de Groot F, Vanko G, Glatzel P. J Phys-Condens Mat. 2009; 21

9. (a) Baldwin MJ, Stemmler TL, Riggsgelasco PJ, Kirk ML, Pennerhahn JE, Pecoraro VL. J Am Chem Soc. 1994; 116:11349-11356.(b) Mukherjee S, Stull JA, Yano J, Stamatatos TC, Pringouri K, Stich TA, Abboud KA, Britt RD, Yachandra VK, Christou G. Proc Natl Acad Sci USA. 2012; 109:2257-2262. [PubMed: 22308383]

10. Messinger J, Robblee JH, Yu WO, Sauer K, Yachandra VK, Klein MP. J Am Chem Soc. 1997; 119:11349-11350.

11. Cady CW, Crabtree RH, Brudvig GW. Coord Chem Rev. 2008; 252:444-455. [PubMed: 21037800] 


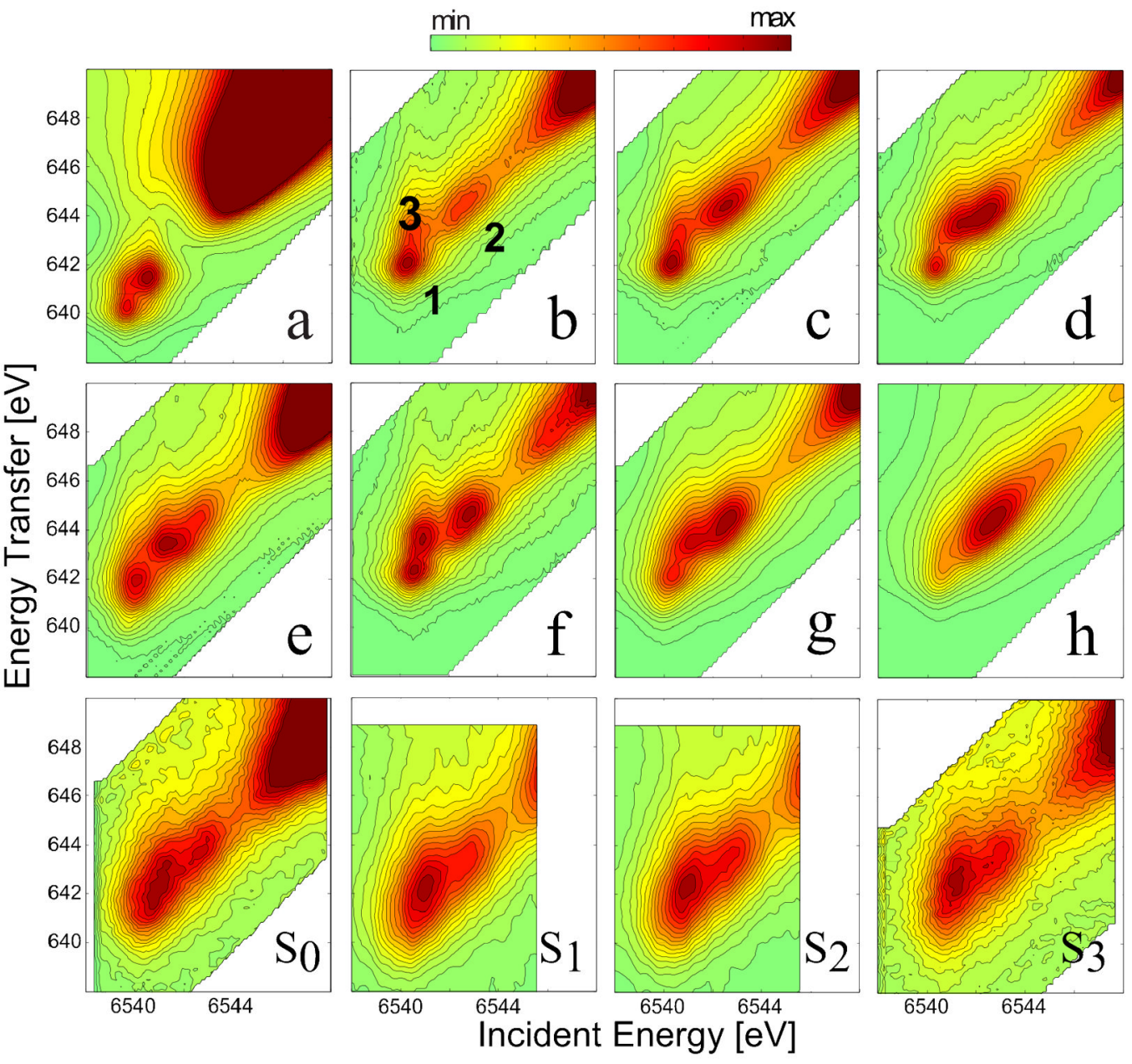

Figure 1.

Contour plots of Mn 1s2p RIXS planes of model compounds and the OEC in PS II in the $\mathrm{S}_{0}$ to $\mathrm{S}_{3}$ states. (a) $\mathrm{Mn}^{\mathrm{II}} \mathrm{O}$, (b) $\operatorname{salpn}_{2} \mathrm{Mn}^{\mathrm{IV}}{ }_{2}(\mathrm{OH})_{2}$, (c) $\operatorname{salpn}_{2} \mathrm{Mn}^{\mathrm{IV}}{ }_{2}(\mathrm{O})(\mathrm{OH})$, (d) salpn $_{2} \mathrm{Mn}^{\mathrm{IV}}{ }_{2}(\mathrm{O})_{2}$, (e) phen ${ }_{4} \mathrm{Mn}^{\mathrm{IV}}{ }_{2}(\mathrm{O})_{2}$, (f) $\mathrm{Mn}^{\mathrm{IV}}{ }_{3} \mathrm{Ca}_{2},(\mathrm{~g}) \mathrm{Mn}^{\mathrm{IV}}{ }_{3}(\mathrm{O})_{4} \mathrm{Acbpy}$, (h) $\mathrm{Mn}^{\mathrm{IV}}(\mathrm{O})_{2}$. The energy axes are identical for all spectra. The intensity is normalized to the maximum in the pre-edge region. for all spectra. 


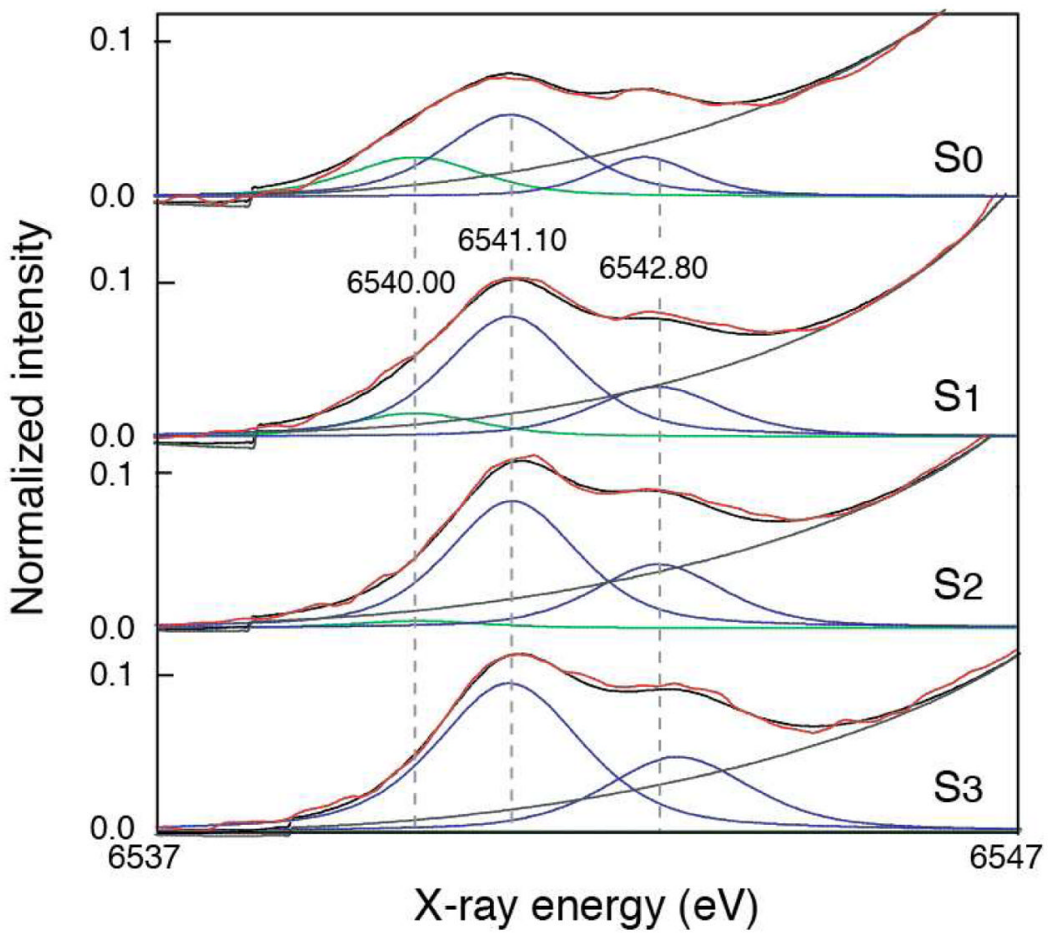

Figure 2.

$\mathrm{K}$ absorption pre-edges and fit of Mn in PS II (red, experimental data; black, fit; blue and green, peak components; gray, background). The dashed lines are guides to the eye. 


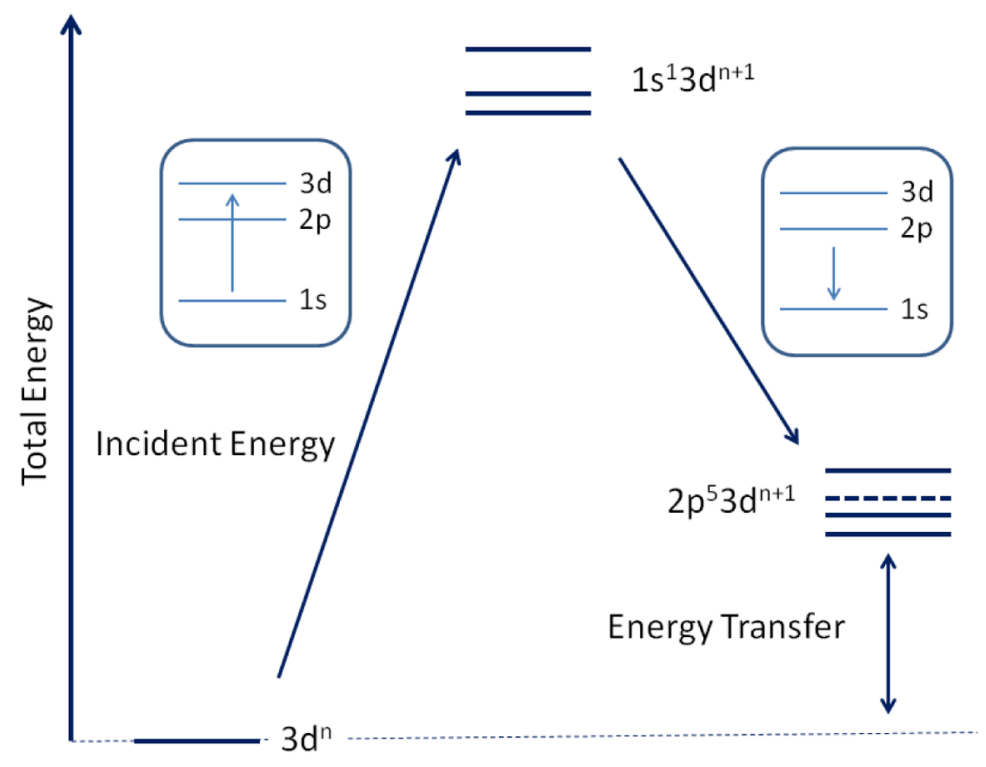

\section{Scheme 1.}

Total energy diagram for the $1 \mathrm{~s} 2 \mathrm{p}$ RIXS process. The fine splitting of the states in the intermediate and final state is indicated. The dashed line represents a final state that arises from $2 \mathrm{p} 3 \mathrm{~d}$ interactions that are absent in the intermediate state.. 